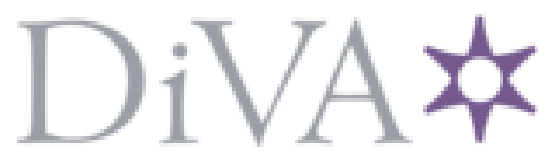

http://www.diva-portal.org

This is the published version of a paper published in Work: A journal of Prevention, Assesment and rehabilitation.

Citation for the original published paper (version of record):

Jansson, I., Björklund, A., Perseius, K-I., Gunnarsson, A B. (2015)

The concept of 'work ability' from the view point of employers.

Work: A journal of Prevention, Assesment and rehabilitation, 52(1): 153-167

http://dx.doi.org/10.3233/WOR-152037

Access to the published version may require subscription.

N.B. When citing this work, cite the original published paper.

Permanent link to this version:

http://urn.kb.se/resolve?urn=urn:nbn:se:hj:diva-28212 


\title{
The concept of 'work ability' from the view point of employers
}

\author{
Inger Jansson $^{\mathrm{a}, \mathrm{b}, *}$, Anita Björklund ${ }^{\mathrm{a}}$, Kent-Inge Perseius ${ }^{\mathrm{b}, \mathrm{c}}$ and A. Birgitta Gunnarsson ${ }^{\mathrm{d}}$ \\ ${ }^{a}$ Department of Rehabilitation, School of Health Sciences, Jönköping, Sweden \\ ${ }^{\mathrm{b}}$ Nyckeln Competence Centre for Pedagogics in Healthcare, Kalmar County Hospital, Kalmar, Sweden \\ ${ }^{\mathrm{c}}$ Department of Neurobiology, Care Sciences and Society, Karolinska Institutet, Stockholm, Sweden \\ ${ }^{\mathrm{d}}$ Unit for Research and Development, Kronoberg County Council, Växjö, Sweden
}

Received 23 October 2013

Accepted 4 September 2014

\begin{abstract}
.
BACKGROUND: Since work ability is manifested in working life and "bought" by employers, employers perceptions of the concept are important to understand. Studies have shown that people with health problems want to take part in the labour market, but experience difficulties in gaining access. Additionally, studies have demonstrated the doubt felt by employers when they consider hiring a person with a disability.

OBJECTIVE: The aim was to identify and characterise employers' conceptions of work ability.

METHODS: The study design was qualitative with a phenomenographic approach. Six male and six female employers from various workplaces and geographical areas in Sweden were interviewed.

RESULTS: Three domains were identified: employees' contributions to work ability, employers' contributions to work ability and circumstances with limited work ability. Work ability was regarded as a tool in production and its output, production, was the main issue. The employees' commitment and interest could bridge other shortcomings.

CONCLUSIONS: The employers highlighted their own contributions in shaping work ability in order to fit with work circumstances. Health problems were not the only limiting issues; other circumstances, such as individual characteristics and contextual factors, could limit work ability too. Knowing the importance of commitment and interest is valuable in work rehabilitation.
\end{abstract}

Keywords: Disability, vocational rehabilitation, work demand

\section{Introduction}

\subsection{Work ability}

Since work ability is an ability that is manifested and used in working life and "bought" by employers, their perceptions of the concept are important to understand. Knowledge of the expectations and needs employers have in terms of work ability will make it easier

${ }^{*}$ Corresponding author: Inger Jansson, Nyckeln Competence Centre for Pedagogics in Healthcare, Kalmar County Hospital, SE39185 Kalmar, Sweden. Tel.: +46 70 2709411; E-mail: ingerja@ ltkalmar.se. to adapt the work situation for individuals with disabilities. A better understanding of employers' fears and concerns with regard to work ability can help us to better highlight the resources that people with disabilities can contribute with to the workplace and under what circumstances they can be utilized [1].

Work ability is a crucial and debated concept with importance for both society and the individual. The concept can be regarded from different perspectives. However, for the purpose to understand aspects of disability related to work the medical insurance and the rehabilitation perspectives are the most relevant. From a medical insurance perspective, the objective is to decide whether or not a person is entitled to sickness ben- 
efit. It entails an orientation towards disability with focus on a person's functional and activity limitations due to illness or disease [2-4]. From a rehabilitation perspective, the purpose is to improve an individual's work ability after injury or illness, and work ability is often described as an interaction between the person, the task and the environment [2 11]. There has been less focus on the results of work ability, i.e. the product. Hence, a third, less understood, perspective of work ability can be identified from an employer's point of view, i.e. if anything is produced or not [11-13]. Consequently, this study focuses on this perspective.

Employability is closely related to work ability and, as with work ability, it describes the transition into or out of the labour market. Employability refers to an individual's possibility of being employed [14|15]. Definitions of employability range from narrow descriptions only covering an individual's generic skills and personal characteristics to broader descriptions also covering external demand factors [14-17].

\subsection{Work demands}

Work demands can vary depending on work areas and work situations. They can also vary over time in accordance with societal and technical developments. During the agrarian and industrialisation eras, work required primarily human musculoskeletal efforts [18]. The development of technology has to a large extent reduced biomechanical demands and made production more effective, but it has also created new demands. New and developed technology in production means new ways of performing work duties and organising production. Advanced technology together with new industry branches, like knowledge and service branches, make increased demands on employees' cognitive abilities [18].

In order to describe and understand work demands, the concept of 'occupational form', coined by Nelson [19], could be useful. This concept has been elaborated by Kielhofner [5] and Haglund and Henriksson [20]. One aspect of occupational form is cultural, the conventional way of performing a duty [21]. Additionally, three other aspects of the concept of occupational form can be identified, they are: occupational norm, occupational synthesis and occupational circumstances. Occupational norm implies a socio-cultural aspect which is the culture's conception of how a duty should be performed. This conception includes a shared idea of how something should be done. The second aspect, occupational synthesis, refers to the in- dividual's adaptation and acceptance of the occupational form [22]. Finally, the third aspect, occupational circumstances, deals with the current actual circumstances in which the duty is performed. This aspect includes the physical environment as well as social and psychological components. These circumstances may never be fully controlled [520].

\subsection{Work participation}

Work ability and work participation are close related to an individual's occupational identity and occupational competence. To participate in work and identify oneself as a worker enhance achieving work competence i.e. to fulfil expectations and take responsibility [5]. Studies have shown that people with various health problems want to take part in the labour market, but experience difficulties in gaining access to it [23 24]. Work participation among people with disabilities is lower than for people without disabilities both in Sweden [25] and internationally [2627]. In the USA, four out of ten persons with various disabilities were part of the labour market, while the employment rate for non-disabled persons was eight out of ten persons in 2005 [28]. In Sweden, the same pattern has been shown with five out of ten persons with disabilities taking part in the labour market compared to eight of ten without disabilities. Only three of ten with mental health problems are part of working life and this is the lowest frequency among all disability groups [29]. The gap between people with and without disabilities participating in working life is not diminishing; rather it is increasing [25].

\subsection{Employers' concerns}

Additionally, studies have shown that there is uncertainty and doubt among employers when they consider hiring persons with disabilities [30-32], especially among employers with no experience of such hiring [33]. In a qualitative study using semi-structured interviews, employers were asked about their attitudes towards hiring people with various disabilities. The employers expressed concerns regarding three major issues: reactions from others, costs associated with hiring people with disabilities and concerns regarding qualifications and work performance [27]. Nonetheless, employers' responsibility for employees can be traced back as far as to 1200 AD when King Henry I of England passed a law holding masters responsible for their servants' lives and losses which occurred as a 
result of a master's negligence. The degree of responsibility for employees has varied over time, sometimes employer responsibility has been more pronounced, and sometimes workers have been more responsible based on the argument that a worker assumes a degree of risk when taking a job. Nowadays, most countries have health and safety laws which hold employers responsible for providing a safe work environment for their employees [34]. According to the Swedish Work Environment Act, employers are responsible for adapting the work situation to suit their employees' individual prerequisites [35]. Investigations into employers' views on hiring people with disabilities have shown both reluctance and satisfaction [30-33 36]. However, employers' views on work ability are rarely investigated [30 32 36]. The aim of this study was thus to identify and characterise employers' conceptions of work ability.

\section{Method}

\subsection{Study design}

The design of the study was qualitative with a phenomenographic approach. The purpose of phenomenographic research is to reveal qualitatively different ways of experiencing phenomena, building on the idea that there are multiple, diverse interpretations of reality [37-40]. Conceptions are fundamental in phenomenography and they are regarded as dependent both on human activity and thinking. They are also regarded as relational and created in interaction between the person and the external reality [41]. Conceptions are seldom explicit for the individual; they are more like subconscious assumptions that haven't been reflected on [42].

\subsection{Participants}

The participants were chosen strategically in accordance with phenomenography with the purpose of obtaining a variety of views and conceptions. Variation was considered regarding the employers' age, gender and number of years as employers, number of employees, employees' gender and educational requirements, geographical location and type of industry. Inclusion criteria were: employers with a close connection to production, experience of hiring employees, understanding work demands and experience of employee(s) with various disabilities including mental health prob- lems. Exclusion criteria were not having experience of employees with mental health problems. Employers were contacted by telephone and informed of the aim of the study and the inclusion criteria. If they met the inclusion criteria, they were asked to participate. Six men and six women from various workplaces in three different geographical areas in Sweden agreed to participate (Tables 1,2). Five of the workplaces had mainly lower educational requirements while two required higher education. The others had mixed educational requirements. Three of the workplaces employed mostly men, four employed mostly women. The other workplaces had a mixed workforce. Types of work varied according to the differing industry branches (Table 1).

\subsection{Data collection}

Data were collected from December 2012 to March 2013. Individual interviews were performed by the first author (IJ). Before the interviews were undertaken, the employers received an e-mail with information about the study and its aim. A total of twelve interviews were undertaken, each employer was interviewed once. The interviews were undertaken until saturation occurred, lasting between 30 and 90 minutes. Ten interviews were undertaken at the employers' workplaces, two were conducted by phone. All interviews were audiotaped with the permission of the employers. The verbatim transcriptions were performed by a professional secretary working in health care and thus working with professional secrecy.

The interview questions were semi-structured and open-ended, allowing the participants to choose aspects of the phenomenon on which he/she wished to elaborate [39]. Each interview was divided into two parts. After asking the main question, concerning conceptions of work ability, a question regarding the impact from mental health problems on work ability was posed. The results emanating from the second question will be published later. The interviews started with some opening questions about the workplace and production followed by questions on demographic data. Then the main question was asked - "How do you perceive work ability?" Probing questions like "Can you please explain that further?" were used with the purpose of uncovering implicit meanings [39]. The concept of work ability was presented without explicit definitions or explanations with the purpose of reaching the participants' unreflective conceptions of the phenomenon [42]. 
Table 1

Branches of industry according to Swedish Standard Industrial Classification represented in the study

\begin{tabular}{|c|c|c|}
\hline & Branch of industry & $\begin{array}{l}\text { Industries represented in the } \\
\text { study (marked with yes/-)* }\end{array}$ \\
\hline A. & Agriculture, forestry and fishing & yes \\
\hline B. & Mining and quarrying & - \\
\hline C. & Manufacturing & yes \\
\hline D. & Electricity, gas, steam and air conditioning supply & yes \\
\hline E. & Water supply; sewerage, waste management and remediation activities & - \\
\hline F. & Construction & yes \\
\hline G. & Wholesale and retail trade; repair of motor vehicles and motorcycles & yes \\
\hline H. & Transportation and storage & yes \\
\hline I. & Accommodation and food service activities & yes \\
\hline $\mathrm{J}$. & Information and communication & yes \\
\hline $\mathrm{K}$. & Financial and insurance activities & - \\
\hline L. & Real estate activities & - \\
\hline M. & Professional, scientific and technical activities & yes \\
\hline $\mathrm{N}$. & Administrative and support service activities & yes \\
\hline $\mathrm{O}$. & Public administration and defence; compulsory social security & - \\
\hline P. & Education & yes \\
\hline Q. & Human health and social work activities & yes \\
\hline R. & Arts entertainment and recreation & yes \\
\hline S. & Other service activities & yes \\
\hline T. & $\begin{array}{l}\text { Activities of households as employers; undifferentiated goods and services producing activities of } \\
\text { households for own use }\end{array}$ & yes \\
\hline $\mathrm{U}$. & Activities of extraterritorial organisations and bodies & - \\
\hline
\end{tabular}

* One workplace may represent several industry branches.

Table 2

Demographic description of employers $(n=12)$ and number of employees at workplaces

\begin{tabular}{lll}
\hline Participants' demographics $(n=12)$ & Range & $\mathrm{f}$ \\
\hline Women & & 6 \\
Men & & 6 \\
Age & $36-45$ & 4 \\
& $46-55$ & 4 \\
& $56-65$ & 4 \\
Number of years as employer & & \\
& $2-5$ & 4 \\
& $6-10$ & 3 \\
Number of employees at workplace & $11-25$ & 5 \\
& $5-20$ & 3 \\
& $21-80$ & 4 \\
& $81-170$ & 4 \\
& $171-1000$ & 1 \\
\hline
\end{tabular}

\subsection{Data analysis}

The data were analysed following the phenomenographic method [37|39]. All data were handled as one dataset. The focus of the analysis was on differences and similarities regarding the phenomenon, i.e. work ability. The analysis followed the following steps:

1) Familiarisation; the data was listened to and repeatedly read through in order to become acquainted with the content.

2) Condensation; the most significant utterances regarding the aim of the study were identified.
3) Comparison; the utterances were compared with each other to identify differences and similarities qualitatively.

4) Grouping; utterances that appeared similar were grouped and put together in categories.

5) Labelling; suitable semantic expressions for the categories were used.

6) Contrasting; the categories were compared regarding similarities and differences.

7) Logical relationships between the categories and their representations in the form of various dimensions of the phenomenon were revealed.

Besides, as a form of member checking the strategies repetition, requests for clarification and confirmation were applied all through the interviews [39].

The analysis resulted in three dimensions with respectively five, five and three categories. Steps 1-3 were conducted by the first and last author. Steps 4-7 were conducted by all four authors and all steps were repeated several times.

In order to enhance trustworthiness [42] the authors represented a broad area of experience. One was an occupational therapist/PhD student/interviewer (IJ), one was an occupational therapist/experienced researcher $(\mathrm{AB})$, one was a nurse/researcher (KIP) and one was an occupational therapist/researcher (BG).

Employers may have different positions in a company and more or less knowledge about how the work 
is actually performed. Therefore, in order to strengthen credibility, we chose participants who were mainly employers in close contact with production and with experience of recruiting employees. Credibility was also strengthened by the detailed description of the various steps following the phenomenographic method and the quotes provided which illustrate all categories [39 43]. Credibility was further strengthened by all authors discussing the dimensions, categories and sub-categories until consensus was reached in line with phenomenographic research [39].

Dependability deals with the reliability of the conclusions [43]. Since work can encompass a wide range of situations with varying demands, the aim of this study was to illustrate the concept of work ability from different angles of working life. By choosing employers from various industry branches representing varying demands, we strengthened dependability [39 43]. In order to strengthen dependability so that the study might be repeated, we have provided a detailed description of the data collection procedure.

Transferability deals with the extent to which the results can be applicable to other settings [4344]. Even if the intention of the results from the interviews is not to transfer them to other settings, the authors in this study tried to strengthen transferability by interviewing employers based on a variation regarding age (36-65 years), gender six men/six women), number of years as an employer (2-25 years), number of employees (5-1000), employees' gender and educational requirements, geographical location and industry. Transferability was also enhanced through providing description of the participants and their work places (Tables 1-2), the research process and the results (Table 3, Fig. 1).

To ensure confirmability all authors were engaged in the entire research process. Through reflexive discussions between the researchers awareness of their own influences in the research process were kept in mind. A reflective approach was aimed to maintain during the entire research process.

\subsection{Ethical considerations}

All participants were informed both verbally and in writing about the purpose of the study. They were also repeatedly informed about the possibility of withdrawing from the study at any time without any explanation. Furthermore, they were informed that quotes from the data would be presented in such a way that they would remain anonymous [45]. Participants in the study were employers and they were not in a position of dependence vis-à-vis the research representatives. Since no sensitive personal information was collected, and in accordance with the Swedish act concerning the Ethical Review of Research Involving Humans (2003:460) [46], ethical approval was not required.

\section{Results}

The outcome space of the data, describing the employers' conceptions of work ability, was revealed in three dimensions. These dimensions are: "The individual's contribution to work ability", "The employer's contribution to work ability" and "Circumstances with limited work ability". Two dimensions are comprised of five categories each and the third dimension is comprised of three categories (Table 3).

\subsection{The individual's contribution to work ability}

The first dimension describes what employers perceive and experience as important features of an individual for work ability. Five categories regarding the individual's contribution to work ability were identified: "Being of service", "Commitment, interest and a wish to develop", "Ability to communicate and be internally and externally sociable", "Being your own supervisor" and "Delivering lean production - on time"

\subsubsection{Being of service}

Being of service includes being physically, mentally and cognitively available. Most employers described demands on a basic physical ability related to their own workplace as a prerequisite to having work ability. The description of physical ability could range from demands on workers to sit still doing monotonous work to being able to withstand heavy physical work under adverse weather conditions. Manual dexterity and coordination skills were some additional examples given. Being able to use and handle one's physical abilities was also stressed.

"When you say physical prerequisites, you can have a slender, tiny girl who nevertheless adapts her work so she can stock up articles as well as a big strong guy." (Employer 1)

Some degree of mental abilities, such as self-reflection and the ability to cope with stress, conflicts and frustrating situations, were also regarded as basic abilities by the employers. Self-reflection was considered 
Table 3

Dimensions and categories of employers' conceptions of work ability

\begin{tabular}{ll}
\hline Dimensions & Categories \\
\hline The individual's contribution to work ability & Being of service \\
& Ability to communicate and be internally and externally sociable \\
& Commitment, interest and a will to develop \\
& Being your own supervisor \\
& Delivering lean production \\
The employers' contribution to work ability & Providing a work environment and shaping work ability \\
& Providing a social team spirit \\
& Motivating through information and involvement \\
& Coaching and supporting \\
& Managing and organizing work \\
Circumstances with limited work ability & Individual characteristics \\
& Contextual factors \\
& Limited adaptation ability \\
\hline
\end{tabular}

important because it could enable employees to reflect on how to improve their work ability.

According to the employers, stress occurred frequently in work situations and needed to be coped with, for instance at deadlines, temporary work peaks and sometimes during longer congested work situations. Coping with frustrating situations and conflicts might be required when employees met complaining or angry customers. Cognitive abilities, like being able to focus on work duties, concentrating on work and ignoring distractions, were also perceived by the employers as prerequisites for work ability.

Having physical, mental and cognitive abilities was not enough for having work ability. The employers expressed that there also had to be endurance in these abilities. Persevering, being patient and not giving up were reported as important. This included tolerating and taking criticism from management so as to improve work ability. Employers with young employees especially expressed the importance of employees tolerating reprimands and setbacks. In their experience, employees were sensitive to reprimands and setbacks and found them difficult to handle, while the employers saw them as an important part of improving work ability.

“...got information from the customer who wasn't satisfied. I talked to her ... Then she showed her claws ... 'But I did what I was supposed to do.' So I had to take her with me and show her. So we checked together. 'Do you think that is OK?' 'No ...' [she said]. So I had to do that, confront her." (Employer 2)

\subsubsection{Ability to communicate and be internally and externally sociable}

Employers regarded being able to communicate and be sociable as important parts of work ability, both in- ternally in contact with management and co-workers, and externally in contact with customers. Levels of communicative and social abilities within the workplace varied from being basic to being more sophisticated. Some types of communication, like informing about non-attendance at work, were perceived as a basic ability, as was being able to communicate and inform others about what one is doing so they can adjust their activities accordingly. The employers also expressed that being a team worker and cooperating and setting up for co-workers as important. Social abilities included having a nice time with co-workers and getting along with them while also accepting and coping with elements of competition in a socially acceptable way.

According to the employers, the ability to communicate and be sociable externally was part of work ability. There could be situations which required being able to explain in detail and in a pedagogical way so that a customer could understand. Being able to communicate also includes discussing and reasoning with frustrated and dissatisfied customers. Social ability was described as being welcoming, responsive and having a sense of service.

"We had an order to broadcast TV sport that they decided to cancel. So broadcasting was shut down on a Saturday when all the men were sitting at home ready to watch TV. So they called us. There were several thousand calls; there's usually a hundred. Everyone just screamed and was insane. There were some [employees] who sat and cried. It was like a shock on the phone. For some it was their first job ...they are nineteen [years] and older." (Employer 3) 


\subsubsection{Commitment, interest and a will to develop}

The employers stressed the importance of employees' commitment and interest in their work and what the workplace stands for. Some employers' expressed that being proud of one's job is also an important part of having good work ability. Being proud of one's job implies that the employee agrees with his or her workplace's values and is willing to engage in the work duties. Commitment and interest were seen as a foundation for work ability. Showing interest and commitment could, according to the employers, bridge other shortcomings. Interest and a desire to learn were considered prerequisites for developing in the worker role. Coming to work just for the money was not enough.

"We don't want those who come just for the salary. You should come here because you want to. It must give you something. Money mustn't be the most important thing, it should be your wish to do a good job". (Employer 1)

\subsubsection{Being your own supervisor}

According to the employers, having good work ability included the individual being able to be his or her own supervisor. This entails being reliable, taking the initiative, being flexible, being aware of rules and having an overview of the various production steps.

"There's a range of duties so you have to be proactive in finding new duties when things slow down. There can't be someone running and telling you... now that you don't have much to do, do a bit of dusting here and there ... and do some cleaning over there. You are expected to take responsibility for that yourself. Supervisors - we can't afford them." (Employer 4)

From the employers' perspective, being reliable refers to taking responsibility and being able to work independently, and also knowing when to ask for help. Time serving, i.e. just doing work obvious to management, had sometimes been experienced by the employers and was related to limited work ability. Being able to take the initiative was considered important but most important was taking the right initiatives, i.e. recognising which duties were most urgent and important. The ability to be flexible was exemplified by the employers with coping with changes in work routines and adjusting to changed work demands like workload peaks, new routines or new ways of performing work duties.

"Taking creative responsibility... I'd say that it's needed in all situations... that you are prepared to develop what you do, 'but couldn't we do it like this instead...' to change and develop in a positive way for the workplace." (Employer 5)

Another aspect of work ability according to the employers is being able to have an overview of the various steps in production. This includes knowing and understanding the other employees' roles, making it possible to stay one step ahead. Understanding what the others do and what their responsibilities are increases the possibility of delivering a good job at the next step.

“... that you are good internal customers and suppliers, that you don't just chuck a product at an internal customer, rather... 'this is my friend, he wants a good result from me,' that you consider the recipient... and you know the recipient and would be ashamed of doing a bad job for an internal customer." (Employer 7)

\subsubsection{Delivering lean production on time}

Being productive as an employee is considered a basic assumption among the employers. Without production, in any sense of the word, there is no reason to employ someone. According to the employers, demands on employees are sometimes too high but the employers didn't perceive that they had the power to change this. They referred to competition and demands from the market.

"Everybody has to make savings you know... and our competitors... if we don't get the order someone else will." (Employer 2)

The employers stressed that work duties should be done in accordance with the rules, in the most effective way.

Being aware of and respecting workplace rules are important parts of work ability according to the employers. Since rules may change, it is also important to be able to update rules and adapt, accept and apply them. Keeping to the rules regarding working hours and coffee and lunch breaks was also considered important.

“... that people understand how important it is to follow our rules... we have an incredible number of rules... so that part, that you follow our rules because they are important for safety." (Employer 6)

Mistakes should be minimised and work duties should be performed without unnecessary steps.

"Or being too detailed ... this is what I said '... but why? This won't show and wasn't needed? And 
you have been working with this for two hours. Who will pay for that?"' (Employer 8)

Minimising and applying lean methods to production should not affect quality and there were demands from the employers for accuracy, but not excessive work, in production. Delivering lean production also meant managing time frames and delivering on time. This meant, according to the employers, making the perfect match between demands on quality and lean production. It may be more difficult to introduce this way of thinking to employees who are familiar with their work duties, and therefore have difficulties in accepting a lean way of performing duties instead of the familiar way of doing them.

\subsection{The employer's contribution to work ability}

The second dimension describes the employers' conceptions of features they contribute with when shaping and forming employees' work ability to fit specific work demands in their workplace. Their contribution is described in the following categories: "Providing a work environment and shaping work ability", "Motivating through information and involvement", "Providing a social team spirit", "Coaching and supporting" and "Managing and organising work".

"As the boss, I have to ensure that they work flat out and I have to have meetings with them and talk about how they feel and if there is something we can do here [in the workplace] or if there is something going on at home." (Employer 7)

\subsubsection{Providing a work environment and shaping work ability}

The employers expressed their responsibility for providing a physical environment with the necessary technical devices for facilitating work performance. They also spoke of inducting their employees and educating them about the "right way" of performing duties so as to develop work ability in a specific work situation. This induction is often performed by experienced co-workers. The "right way" of doing duties is based on quality, lean production and safety demands. The employers expressed various allowances they made to individual ways of performing work duties depending on business.

"We teach new ways, new methods to be able to manage the orders we have today. What we did in five hours we now have to do in two and a half hours. So we have a trainer who trains the employ- ees how to handle equipment ergonomically but also how to plan their duties in order to be time effective". (Employer 2)

\subsubsection{Providing a social team spirit}

The employers spoke of their contribution to creating a feeling of wellbeing and good team spirit among the employees so as to maximise work ability and cooperation which in turn is enhanced if co-workers know each other. Good team spirit was supposedly enhanced by team-building activities outside work. These activities could be performed as a company kick-off either ahead of challenging work demands or after, as a reward after a difficult achievement.

"In periods of high demand and pressure... it has led to less chatting during coffee breaks. They haven't taken the time to sit down and talk to each other... and I can see that the developing discussions that are needed for a good result aren't happening." (Employer 10)

\subsubsection{Motivating through information and involvement}

According to the employers, they played an important role in motivating employee's in order to enhance their work ability. Involving employees could include providing information and taking part in financial results. This involvement was regarded as a way of motivating employees.

"Open reporting. . . you can take part in financial reports, this creates commitment and participation, it creates an interest, that you are part of it and have influence, 'I am also in control of the situation.", (Employer 4)

There were also descriptions of providing employees with information about the employer's total costs of their employees, including salaries, work clothes, etc. These costs were then calculated per hour and related to how much the workplace had to produce per hour to pay the costs of the employees and also be profitable and have a chance of surviving. This open financial accounting was experienced as a good way of making employees aware of economic realities. In the employers' experience, explaining how costs and earnings were related to each other enhanced their employees' motivation and work ability. This way of explaining economic circumstances was more common among employers with few employees. 
"Every six months... I go through how much they cost the company... and how much we have to make...so I count it down to the minute level per employee... and explain costs like salaries and rent... so we have to make this much money and a little bit more, otherwise it will all go to hell. And everybody is motivated by that." (Employer 9)

\subsubsection{Coaching and supporting}

Coaching through feedback was regarded by the employers as an important way of forming work ability. Coaching was often adapted to an individual's needs. Sometimes it had to be more frequent and focussed on giving credit. Sometimes frank and clear language was considered more as coaching. Sometimes there was a need to coach and encourage at critical times.

Regarding providing conditions for developing good work ability, the employers expressed that they tried to support the employees to stay healthy and feel good. Through regular conversations, the employees were encouraged to express any feelings of being overwhelmed, having problems or difficulties. The employers spoke of the advantages of knowing about problems before they became unmanageable, thus being able to adapt circumstances. Also, understanding why someone is not producing as usual facilitates and prompts a more tolerant attitude.

"He had been on sick leave several times, said something about problems at home but he didn't want to talk about it... Although we have known each other for twenty two years... I don't take it personally, it's his choice but as I see it maybe I could have helped him in some way, supported him...somewhere the role as business manager and friend... where is the line between business manager and friend. As a business manager I automatically keep some distance... but on the other hand, we have known each other for so many years...you want to help as a fellowman... and knowing makes you more tolerant." (Employer 11)

\subsubsection{Managing and organising work}

The employers described their responsibility to manage and organise work. In smaller workplaces, an employer could manage production directly and adjust work duties almost immediately if they didn't suit an employee.

“... seeing abilities and using them in the right situation.” (Employer 9)
Sometimes the employers created a team of workers with complementary abilities and knowledge that matched a special assignment. When a new assignment with different demands came along, other team members with other complementary abilities were chosen. In other cases, the organisation of the work was more structured and employees had to follow the organisation and not what the employer said. In these cases, the employers stressed the importance of clarifying and maintaining the organisation. The employers also expressed that all workers had to be interchangeable in the organisation; thus, there was a requirement for having the abilities in common.

\subsection{Circumstances with limited work ability}

The third dimension describes the employers' conceptions of situations with limited work ability. This dimension includes the following categories: "Situations within the individual", "Situations outside the individual" and "Situations with young employees".

The employers expressed limited work ability as something related to specific situations. This could be something within the individual interfering negatively with work performance, something outside the individual or something transient such as young inexperienced employees. Experiences of employees with limitations in work performance were perceived as the employee not fitting in with the workplace and the work tasks. One employer concluded that a person hadn't fitted in with their workplace but hopefully would fit better somewhere else.

"Maybe you don't fit in in this industry... maybe you should look for something else." (Employer 7)

\subsubsection{Individual characteristics}

Situations perceived from the employers' perspective as problematic and caused by individuals were, for example, health problems. Other limiting factors within the individual might be personality-related, like being too detailed and formal or lacking interest in work duties. Having too many private commitments was also perceived as interfering with work demands and limiting the ability to work.

"Say you put eighty percentages of your energy on the job and you have to put another eighty percentages at home ... You have so much at home... you are forced to do at home... then there is a high risk it all goes to hell at work." (Employer 12)

Drinking and over consumption of alcohol were other situations regarded as limiting work ability according to the employers. 


\subsection{Contextual factors}

The employers described various situations which limited work ability. These situations could occur in connection with the illness of close relatives. Other situations included relationship problems like romantic problems reported by employers as usually among young employees. Divorces were described as having a huge impact on the ability to focus and concentrate. Other contextual factors reported by the employers as restricting the ability to focus were social problems like having children with problems, lack of housing or home-life being overwhelming with responsibility for children, the home and earning money. Also, positive events like building a new house were experienced as time-consuming and taking commitment and focus from work duties which restricted work ability.

"Two [employees] here are building houses and they ... I have to tell them ... you have to have focus on the job." (Employer 7)

\subsubsection{Limited adaptation ability}

Other situations reported by the employers which exemplify limited work ability were young employees with no work experience seeming to lack the ability to adapt to unspoken, obvious rules in the workplace regarding how to dress, take responsibility for and keep one's desk in order and be on time. This was expressed as a transient phenomenon but the lack of these abilities still impacted on work ability according to the employers.

"No proper manners, they might look like ... well, clothes hanging out and a belt is like ... his underwear visible and ... So, sometimes you have to take a guy and you pull up his pants and you tighten his belt and... 'now you look much better"'. (Employer 4)

\section{Discussion}

The main findings in this study were the employers' conceptions of work ability as a relation between individual abilities formed and shaped in a work setting and resulting in productivity (Fig. 1).

For the employers, the outcome of work ability, productivity, was the main issue. From the employers' point of view, the employees' ability to work was regarded as a tool in production and not a goal in itself. In addition, not only health problems but also other cir-

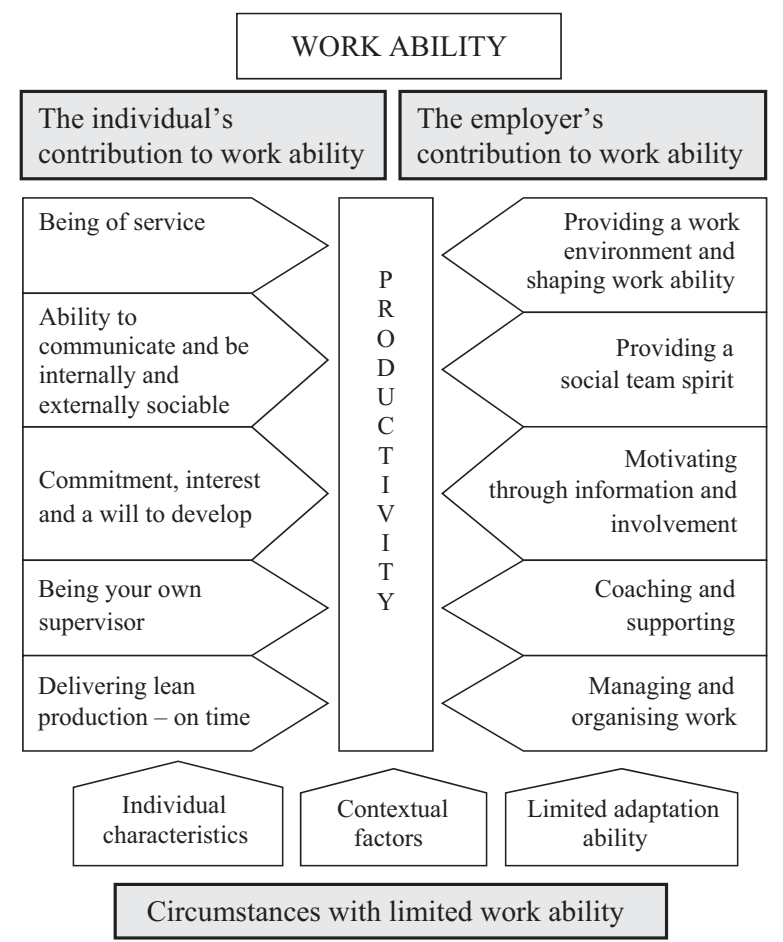

Fig. 1. Outcome space of interrelated categories of description. Relationship between the dimensions and categories of the employers' conception of work ability.

cumstances like individual characteristics, contextual factors and lack of adaptability could limit an individual's work ability.

\subsection{Employees' contributions to work ability}

The basic physical, mental, cognitive, communicative and social abilities of an employee were essential for his or her work ability according to the employers. This is in accordance with previous descriptions of both work ability and employability [33|36|47|48]. However, expectations on abilities could differ depending on the demands of the actual work setting. Nonetheless, according to the employers, it was essential that these abilities endured, whether one had to sit still on a chair or cope with hard outdoor work. To the contrary, the insurance perspective on work ability only stresses the presence of basic abilities as the main concern [2]4]. Similarly, the rehabilitation perspective is also less concerned with endurance [47]. One aspect reported by the employers related to endurance was the ability to take reprimands, something which was considered an important part of work ability and which has been reported in other studies as well [33 49]. Endurance and being able to continue with tasks until 
they are completed can be related to Kielhofner's [5] concept work competence. Endurance and completing tasks have also been identified as important basic work skills which novice employees sometimes needed training in [33|50]. One strategy for increasing endurance was to alternate work tasks when employees became less enthusiastic [50].

The employers emphasised commitment and interest as part of work ability. Commitment and interest are less referred to as basic components of employability skills [17/33] although other studies suggest they are [50 51]. From the employers' point of view, commitment and participation were supposed to be increased through taking part in productivity and viability aspects of the business. This is in accordance with a study by Tuomi et al. [52] showing that influence on work situations improves work ability. The emphasis on employees' commitment is an important feature to bring to rehabilitation settings. What individuals feel commitment to and interest in is a valuable signpost in improving work ability and is an important part of a person's work identity [5].

The employers considered the ability of employees to work independently as a very important part of having work ability. Being expected to work independently yet still keep to the rules and be able to overview production steps, makes high demands on an individual's cognitive abilities. In modern working life, these expectations are common [18|53]. There are expectations on the employee to manage their work independently, take responsibility, prioritise, make decisions and deliver a qualitatively good result in the leanest way [54]. Hagström and Hanson [53] discuss self-management skills as an important part of modern working life. Self-managing includes having the capability for both insight and overview.

\subsection{Employers' contributions to work ability}

The employers described their contribution to shaping and developing work ability for their specific needs as providing a supportive work environment, work task training and creating a feeling of well-being among their employees in order to enhance team work and cooperation. This process of familiarising and introducing the employees at a workplace has been identified among employers working with young novice employees. Strategies like task rotation were used with the purpose of giving the employees experience of new tasks and training them in the workplace [50]. This was also a way of becoming acquainted with and developing team work and cooperation with co-workers [50].
The employers perceived coaching as their responsibility, enabling employees to manage work performance independently. This goal, to enable employees to manage their work performance independently is in line with Kielhofner's concept work competence [5]. Coaching for enhancing work competence was, according to the employers, adapted to the individual's ability. The strategy of coaching employees towards increased work competence was also found in a study dealing with inducting young employees. The strategy used was to progressively allocate and increase responsibility [50]. This way of adapting work tasks to the individual's ability is in line with situational leadership as described by Cubero [55]. Situational leadership includes four main leadership styles: telling, selling, participating and delegating. These styles vary from saying what to do and how to do it (telling) to passing a large amount of responsibility to the employee (delegating). The leadership styles are coordinated with the employee's level of maturity, broken down into four levels where the first level indicates low maturity and the fourth high maturity.

The employers described how their coaching and support could vary. Sometimes their support was frequent, indicating telling leadership and lower employee maturity. Sometimes their support was limited to critical moments indicating participatory or delegating leadership and higher employee maturity.

The employers expressed that knowing when employees' problems affected their work ability was positive, and enabled the employers to adjust demands. This has also been reported in other studies [36 55 56]. Knowing about problems which affect work ability makes it possible to change leadership style. Professional support, i.e. support from someone outside the work place, could be an alternative to adjust demands. However, professional support has been found to rather stigmatize and hinder inclusion in the work place [57]. Employers' attitudes and skills regarding adjustments and accommodations are of vital importance for gaining access to a work place [58]. A more effective rehabilitation strategy can therefore be to support employers to guide and support employees as well as to provide efficient accommodations for their employees with disabilities [57.59].

However, adjusting work conditions according to an individual's needs was not always perceived as possible. The organisation was raised as an obstacle to altering duties according to an employee's needs, and the employers expressed that the organisation was not easy to change. Furthermore, the organisation could some- 
times demand the same ability to perform work tasks from all employees. The possibility for employees to change and regulate work demands depending on their health circumstances has been found to improve perceived work ability [60]. Some of the employers described how they organised work duties according to circumstances involving the employees' abilities. This way of managing the work process with the possibility of harnessing abilities and "using them in the situation" is also an example of situational leadership and may suit people with disabilities better, especially if their work ability fluctuates. The importance of a supportive managerial leadership has been identified as an important factor for employees' wellbeing and health [6162]. Using situational leadership and actively matching the job to the individual employee has been a common practice among employers who have had positive experiences of hiring people with disabilities [56].

The employers' conceptions of work ability were in accordance with descriptions of employability. Employability skills have been formulated as ranging from basic generic skills to more complex skills and also include factors external to the individual [15]. This agreement with the employability concept when asked about conceptions of work ability may indicate a perceived irrelevance of dividing the concepts. For the employers, it may be of less importance what abilities and skills an individual possibly has if these abilities can't be transformed into productivity.

\subsection{Circumstances with limited work ability}

From the employers' perspective, problems with individual characteristics were not the only issues that could limit work ability, contextual factors external to the individual could also be limiting. The employers expressed heavy private commitments among employees as limiting work ability. Combining work and family is the most common way of managing family life and making a living [63-66]. Striving for balance between the family and work spheres seems to be a more or less ongoing process [67]. The so-called workfamily interface [64] has mainly been observed from the work-to-family spill-over but can be described from both directions [65]. The employer's perspective is the family-to-work direction, i.e. spill-over from family to work which they perceive as limiting work ability. Similarly, positive events like building a new house were perceived as limiting work ability. In other studies, the interface between family life and work has been shown to have both stimulating and stressful effects 656869].

\subsection{Employers' perspectives versus medical insurance perspectives on work ability}

According to the results of this study, the employers' views on work ability may be contrasted with the medical insurance view which mainly focuses on the individual's functioning and activities, not specifying what kind of activities and under which circumstances they are performed. Motivational factors are not regarded at all in medical insurance contexts [2 270]. Also, productivity is less considered in medical insurance perspectives and is referred to and defined in a normative way rather than relying on actual circumstances [270]. This discrepancy between employers' perspectives and medical insurance perspectives may be inevitable, but it is still important to understand employers' conceptions of the concept of work ability in order to better harness and adapt abilities among people with disabilities.

\subsection{Work ability related to the concept of occupational form}

The results of this study can be related to the concept of occupational form [5 19:20]. When being inducted at work, an employee is presented with an occupational norm [20] for how duties should be performed at the specific workplace. The norm is expected to be followed and employers describe their coaching role in inducting the employee according to the occupational norm. Commitment to the role of worker could be related to the aspect of occupational synthesis [20]. The employee has integrated and accepted the work duties. To know what to do and when to do it can be seen as related to occupational circumstances. These circumstances are unique and may change, thus the employee needs to adapt to the current situation. The importance of producing in the leanest way and following rules can be seen as fully adapting to the occupational form and its aspects, including following the occupational norm, accepting duties, synthesising them and being able to adapt to circumstances [20].

\subsection{The study's strength and limitations}

Almost all of the employers (twelve of fourteen invited) who were contacted and met the inclusion criteria agreed to participate and fulfilled their participation in the study which strengthens credibility [43].

However, not all industry branches were represented and the companies were mainly small or medium 
sized. The geographical locations varied but were still concentrated to the south of Sweden. There were no employers from e.g. financial, real estate, public administration or defence industries. This may have limited the variation of the conceptions of work ability and thus affected credibility.

Transferability may also be limited to contexts with similar medical insurance system, rehabilitation system, labour market and work culture.

\section{Conclusion}

The employers' conceptions of work ability were multifaceted and related to their need to keep production (business) running. They expressed individual abilities, such as being of service, having the ability to communicate, being interested in developing, and being able to be his or her own supervisor, i.e. work independently as essential for work ability. However, the employers highlighted their own contributions in forming and shaping work ability in order to fit their production and work circumstances. Health problems were not the only things that could be limiting, other circumstances, such as individual characteristics within the employee and contextual factors in the employee's environment could also limit work ability.

The findings regarding the importance of an employee's commitment and interest which, from the employers' point of view, can bridge other shortcomings, is valuable knowledge when planning work rehabilitation.

The employers' experiences and applications of supporting leadership styles are valuable knowledge applicable in the work rehabilitation process. Additionally, their experiences of coaching are important knowledge for improving employees' work competence.

The employers' views of themselves as parts of forming the employees' work ability is important knowledge to consider in the rehabilitation process. This implies that the employers should be involved to a greater extent in the rehabilitation process.

The discrepancy between employers' perspectives and medical insurance perspectives on work ability may be inevitable, but is important to understand not only in rehabilitation settings in order to better harness and adapt the capabilities of people with disabilities but also when organising work tasks and circumstances in the workplace. Employers' views on work ability, as a result of employees' contribution as well as their own contribution, show several similarities with occu- pational therapy theories which stress the interactional feature of all activity performance. This indicates that occupational therapy theories are suitable in the work rehabilitation process.

\section{References}

[1] Gustafsson J, Peralta J P, Danermark B. The employer's perspective on Supported employment for people with disabilities: Successful approaches of Supported employment organizations. J Vocat Rehabil. 2013; 38 99-111. DOI:10.3233/ JVR-130624.

[2] Statens offentliga utredningar (SOU 2009: 89) [Swedish Government Official Reports] Gränslandet mellan sjukdom och arbete. [The borderline between illness and work] (In Swedish). Stockholm: Fritzes offentliga publikationer; 2009.

[3] Seing I, Ståhl C, Nordenfelt L, Bülow P, Ekberg K. Policy and practice of work ability: A negotiation of responsibility in organizing return to work. J Occup Rehabil. 2012; 22(4): 553-64.

[4] Stahl C, Svensson T, Petersson G, Ekberg K. The work ability divide: holistic and reductionistic approaches in Swedish interdisciplinary rehabilitation teams. J Occup Rehabil. 2009; 19 (3): 264.

[5] Kielhofner, G. A Model of Human Occupation: theory andapplication. Baltimore: Williams \& Wilkins, 2008.

[6] Wilcock, A. An occupational perspective of health, Thorofare: Slack, 2006.

[7] Hansen A, Edlund C, Branholm IB. Significant resources needed for return to work after sick leave. Work. 2005; 25(3): 231.

[8] Lindberg, P. The work ability continuum - epidemiological studies of factors promoting sustainable work ability. Stockholm: Karolinska University Press, 2006.

[9] Ilmarinen J. Work ability-a comprehensive concept for occupational health re-search and prevention. Scand J Work Environ Health. 2009; 35(1): 1-5.

[10] Stigmar K, Grahn B, Ekdahl C. Work ability - experiences and perceptions among physicians. Disabil Rehabil. 2010; 32 (21): 1780-9.

[11] Leijten F, Den Heuvel S, Geuskens G, Ybema J, Wind A, Burdorf A, et al. How do older employees with health problems remain productive at work? A qualitative study. J Occup Rehabil. 2013; 23(1): 115-24.

[12] Guidotti TL. What is the Finnish model of work ability? J Occup Environ Med. 2011; 53(9): 1089-90.

[13] Vänni K, Virtanen P, Luukkaala T, Nygård C-H. Relationship between perceived work ability and productivity loss. Int $\mathbf{J}$ Occup Saf Ergon: JOSE. 2012; 18(3): 299-309.

[14] McQuaid RW, Green A, Danson M. Introducing employability. Urban Stud. 2005; 42(2): 191-5.

[15] McQuaid RW, Lindsay C. The concept of employability. Urban Stud. 2005; 42(2): 197-219.

[16] Garsten C, Jacobsson K. Sorting people out: detecting and classifying employability, work capacity and disability at Swedish Public Employment Services. International Sociological Association-conference: Guthenburg, 2011.

[17] Rosenberg S, Heimler R, Morote E-S. Basic employability skills: A triangular design approach. Education \& Training. 2012; 54(1): 7-20. 
[18] Lysaght R, Shaw L, Almas A, Jogia A, Larmour-Trode S. Towards improved measurement of cognitive and behavioural work demands. Work. 2008; 31(1): 1.

[19] Nelson D L. Therapeutic occupation: A definition. Am J Occup Ther. 1996; 50(10): 775.

[20] Haglund L, Henriksson C. Activity-from action to activity. Scand J Caring Sci. 1995; 9(4): 227-34.

[21] Riley J. Shaping textile-making: its occupational forms and domain. J Occup Sci. 2011; 18(4): 322.

[22] Lambert R. Occupation and lifestyle: implications for mental health practice. Br J Occup Ther. 1998; 61(5): 193.

[23] Hetzler A, Melén D, Bjerstedt D. Sjuk-Sverige: försäkringskassan, rehabilitering och utslagning från arbetsmarknaden. [Ill-Sweden: Social insurance agency, rehabili-tation and exclusion from labor market] (In Swedish). Eslöv: B. Östlings bokförlag Symposion, 2005.

[24] Jansson I, Björklund A. The experience of returning to work. Work. 2007; 28(2): 121-34.

[25] Sverige. Statistiska centralbyrån[Sweden statistics] Funktionsnedsattas situation på arbetsmarknaden: 4:e kvartalet 2008. [Disabled persons situation on the labormarket: 4:th quarter 2008] Stockholm: Statistiska centralbyrån; 2009. [cited Sept 05 13] Available from http://www.scb.se/statistik/_publika tioner/AM0503_2008K04_BR_AM78BR0903.pdf.

[26] Loo R. Attitudes toward employing persons with disabilities: A test of the sympathy-discomfort categories. J Appl Soc Psychol. 2004; 34(10): 2200-14.

[27] Lengnick-Hall ML, Gaunt PM, Kulkarni M. Overlooked and underutilized: people with disabilities are an untapped human resource. Hum Resour Manage. 2008; 47(2): 255-73.

[28] Hernandez B, McDonald K, Divilbiss M, Horin E, Velcoff J, Donoso O. Reflections from employers on the disabled workforce: focus groups with healthcare, hospitality and retail administrators. Employee Responsibilities \& Rights Journal. 2008; 20(3): 157-64.

[29] Nationell psykiatrisamordning. Ambition och ansvar: nationell strategi för utveckling av samhällets insatser till personer med psykiska sjukdomar och funktionshinder: slutbetänkande. [National psychiatric coordination. Ambition and responsibility: A national strategy for development of societal efforts for persons with psychiatric disease and disability: final report] (In Swe-dish) Stockholm: Fritze, 2006.

[30] Corrigan PW, Kuwabara S, Tsang T, Shi K, Larson J, Lama CS, et al. Disability and work-related attitudes in employers from Beijing, Chicago, and Hong Kong. Int J Re-habil Res. 2008; 31(4): 347.

[31] Fraser R, Ajzen I, Johnson K, Hebert J, Chan F. Understanding employers' hiring intention in relation to qualified workers with disabilities. J Vocat Rehabil. 2011; 35(1): 1-11.

[32] Hartnett HP, Stuart H, Thurman H, Loy B, Batiste LC. Employers' perceptions of the benefits of workplace accommodations: reasons to hire, retain and promote people with disabilities. J Vocat Rehabil. 2011; 34(1): 17-23.

[33] Ju S, Roberts E, Zhang D. Employer attitudes toward workers with disabilities: A review of research in the past decade. $\mathrm{J}$ Vocat Rehabil. 2013; 38(2): 113-23.

[34] Henshaw JL, Gaffney SH, Madl AK, Paustenbach DJ. The employer's responsibility to maintain a safe and healthful work environment: An historical review of societal expectations and industrial practices. Employee Responsibilities and Rights Journal. 2007; 19(3): 173-92.

[35] Arbetsmiljöverket. Arbetsmiljölagen och dess förordning med kommentarer i lydelse den 1 augusti 2011 [The work envi-ronment act and regulation with comments 1 august
2011] (In Swedish) (Cited Aug 13 13) Available from http:// www.av.se/dokument/publikationer/bocker/h008.pdf.

[36] Tse S. What do employers think about employing people with experience of mental illness in New Zealand workplaces? Work. 2004; 23(3): 267.

[37] Marton F, Booth S. Learning and awareness. New Jersey: Lawrence Erlbaum Associates, 1997.

[38] Sjöström B, Dahlgren LO. Applying phenomenography in nursing research. J Adv Nurs. 2002; 40(3): 339-45.

[39] Stenfors-Hayes T, Hult H, Dahlgren MA. A phenomenographic approach to research in medical education. Med Educ. 2013; 47(3): 261-70.

[40] Dahlgren LO, Fallsberg M. Phenomenography as a qualitative approach in social pharmacy research. J Soc Adm Pharm. 1991; 8: 150-156.

[41] Svensson L. Theoretical foundations of phenomenography. Higher Education Research and Development. 1997; 16(2): 159-71.

[42] Barnard A, McCosker H, Gerber R. Phenomenography: A qualitative research approach for exploring understanding in health care. Qual Health Res. 1999; 9(2): 212.

[43] Kazdin AE. Research design in clinical psychology. $4^{\text {th }}$ ed. Boston, MA: Allyn and Bacon, 2003.

[44] Sin S. Considerations of quality in phenomenographic research. Int J Qual Methods. 2010; 9(4): 305-319.

[45] Vetenskapsrådet [Swedish research council] God forskningssed [Good research practice] (In Swedish). Stockholm: Vetenskapsrådet, 2011.

[46] The act concerning the ethical review of research involving humans (SFS 2003:460). Stockholm: Ministry of education and research, 2003.

[47] Finger ME, Escorpizo R, Glässel A, Gmünder HP, Lückenkemper $\mathrm{M}$, Chan $\mathrm{C}$, et al. ICF core set for vocational rehabilitation: results of an international consensus conference. Disability \& Rehabilitation. 2012; 34(5): 429-38.

[48] Nilsson S, Ekberg K. Employability and work ability: Returning to the labour market after long-term absence. Work. 2013; 44(4): 449-57.

[49] Hand C, Tryssenaar J. Small business employers' views on hiring individuals with mental illness. Psychiatr Rehabil J. 2006; 29(3): 166-73.

[50] Smith E, Comyn P. The development of employability skills in novice workers. National Centre for Vocational Education Research L. 2003; 1-74096-165-X.

[51] Ilmarinen J, Tuomi K, Seitsamo J. New dimensions of work ability. International Congress Series. 2005; 1280: 3-7.

[52] Tuomi K, Vanhala S, Nykyri E, Janhonen M. Organizational practices, work demands and the well-being of employees: a follow-up study in the metal industry and retail trade. Occupational Medicine (Oxford, England). 2004; 54(2): 115-21.

53] Hagström T, Hanson M. Flexible work contexts and human competence: à transaction frame of reference and empirical illustrations. In: Bron A, Schemmann M. editors. Knowledge Society, Information Society and Adult Education. Trends, Issues, Challenges. Bochum Studies in Adult Education, 2003.

[54] Graffam J, Shinkfield A, Smith K, Pol-zin U. Factors that influence employer decisions in hiring and retaining an employee with a disability. J Vocat Rehabil. 2002; 17(3): 175.

[55] Cubero CG. Situational leadership and persons with disabilities. Work. 2007; 29(4): 351-6.

[56] Gilbride D, Stensrud R, Vandergoot D, Golden K. Identification of the characteristics of work environments and employers open to hiring and accommodating people with disabilities. Rehabil Couns Bull. 2003; 46(3): 130. 
[57] Hagner D, Cooney B. Building employer capacity to support employees with severe disabilities in the workplace. Work. 2003; 21(1): 77-82

[58] Jakobsen K, Svendsen E. Employers' perspective: When a return to work is the objective for persons with reduced mobility. Work. 2013; 44(2): 145-153. DOI 10.3233/WOR-201201385 .

[59] Unger D, Kregel J. Employers' knowledge and utilization of accommodations. Work. 2003; 21(1): 5-15.

[60] Johansson G, Hultin H, Möller J, Hallqvist J, Kjellberg K. The impact of ad-justment latitude on self-assessed work ability in regard to gender and occupational type. Scand J Occup Ther. 2012; 19(4): 350-9.

[61] Westerlund H, Nyberg A, Bernin P, Hyde M, Oxenstierna G, Jäppinen P, Väänänen A, Theorell T. Managerial leadership is associated with employee stress, health, and sickness absence independently of the demand-control-support model. Work. 2010; 37(1): 71-79.

[62] Nyberg A, Holmberg I, Bernin P, Alderling M, Åkerblom S, Widerszal-Bazyl M, Magrin M E, Hasselhorn HM, MIlczarek M, D’Angelo G, Denk M, Westerlund H, Theorell T. Destructive managerial leadership and psychological well-being among employees in Swedish, Polish and Italian hotels. Work. 2011; 39(3): 267-281.

[63] Bratberg E, Dahl S-Å, Risa AE. 'The double burden': do com- binations of career and family obligations increase sickness absence among women? Eur Sociol Rev. 2002; 18(2): 233-49.

[64] Grzywacz JG, Marks NF. Reconceptualizing the work-family interface: An eco-logical perspective on the correlates of positive and negative spillover between work and family. J Occup Health Psychol. 2000; 5(1): 111-2.

[65] Stevens DP, Minnotte KL, Mannon SE, Kiger G. Examining the "neglected side of the work-family interface": antecedents of positive and negative family-to-work spillover. J Fam Issues. 2007 ; 28(2): 242-62.

[66] Håkansson C, Ahlborg Jr G. Perceptions of employment, domestic work, and leisure as predictors of health among women and men. J Occup Sci. 2010; 17: 150-7.

[67] Reece KT, Davis JA, Polatajko HJ. The representations of work-life balance in Canadian newspapers. Work. 2009; 32(4): 431-42.

[68] Dugan AG, Matthews RA, Barnes-Farrell JL. Understanding the roles of sub-jective and objective aspects of time in the work-family interface. Community Work Fam. 2012; 15(2): 149-72.

[69] Oomens S, Geurts S, Scheepers P. Combining work and family in the Netherlands: Blessing or burden for one's mental health? Int J Law Psychiatry. 2007; 30(4-5): 369-84.

[70] Tengland P-A. The concept of work ability. J Occup Rehabil. 2011; 21(2): 275-85. 